\title{
Do mito da cura à preservação da função: a contemporaneidade da jovem Geriatria
}

From the myth of cure to the preservation of functions: the contemporaneity of the young Geriatrics

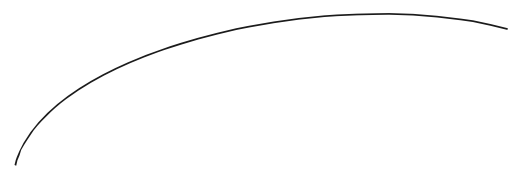

Nos antigos textos egípcios, gregos e romanos, assim como em escritos religiosos, como a Bíblia, já encontramos referências sobre o envelhecimento humano e seus problemas, em geral com conteúdo moral ou com conselhos sobre tratamentos empíricos. Não obstante, a Geriatria é uma das mais jovens especialidades médicas.

O primeiro livro texto sobre o assunto, Geriatrics: The Diseases of Old Age and Their Treatment, foi escrito pelo norte-americano Ignatz Nascher em 1914. Contudo, há concordância mais ou menos consensual de que os fundamentos da especialidade foram desenvolvidos posteriormente, nos anos 30 do século passado, a partir da abordagem original que a médica inglesa, Dra. Marjorie Warren (1897-1960), adotou ao assumir em Londres, a direção de uma enfermaria para doentes crônicos pobres, no West Middlesex Hospital. Lá ela encontrou, institucionalizados, um grande número de idosos portadores de condições não diagnosticadas e inadequadamente tratadas.

Visões simplificadas e em geral bastante negativas do envelhecimento são comumente compartilhadas por indivíduos de diferentes classes sociais, de variados níveis culturais e profissões, sendo comum certo pessimismo imobilizador, mesmo entre profissionais de saúde não-especializados na área de envelhecimento. No entanto, a população idosa é basicamente heterogênea na sua composição, uma vez que é formada por indivíduos em diferentes condições de saúde, com diferentes expectativas de vida, tanto em termos de sua extensão quanto de sua qualidade.

O envelhecimento é fator de risco importante para muitas doenças e é comum que indivíduos idosos sejam portadores de mais de uma morbidade. Todavia, o papel que tais condições mórbidas representam na determinação da condição de vida do idoso deve ser visto sob prisma adequado, ou seja, devemos sempre nos perguntar o quanto tais condições interferem na autonomia - capacidade de decisão - e na independência - capacidade de execução de atividades - desses indivíduos. 
Estes conceitos são o cerne da moderna Geriatria, à qual foram agregadas outras categorias fundamentais: funcionalidade, avaliação geriátrica ampla, síndromes geriátricas, fragilidade, entre outras. Conceitos, sem dúvida, da maior importância para se realizar saltos sucessivos no entendimento do processo de envelhecimento, no desenvolvimento de instrumentos de avaliação e na estruturação de programas de tratamento e reabilitação de indivíduos idosos.

Identificar e tratar doenças continuam sendo objetivos para o geriatra moderno; mas isto é insuficiente, já que conhecer como o idoso está exercendo suas tarefas no dia-a-dia e o seu grau de satisfação exige que o médico investigue desde funções básicas - como independência para alimentar-se, banhar-se, mobilizar-se, higienizar-se - até funções mais complexas - como trabalho, lazer e religião. A esta chamamos de avaliação funcional e, quando associada à avaliação das funções mentais do paciente, isto é, de suas capacidades cognitivas e humor, assim como a presença de distúrbios comportamentais, nos fornece um quadro que vai bem além da simples lista de patologias.

De acordo com os mais modernos conceitos gerontológicos, o idoso que mantém sua autodeterminação e prescinde de qualquer ajuda ou supervisão para se realizar no dia-a-dia deve ser considerado saudável, ainda que portador de uma ou mais doenças crônicas. Decorre daí o conceito de capacidade funcional, a capacidade de manter as habilidades físicas e mentais necessárias para uma vida independente e autônoma. Do ponto de vista da moderna Geriatria, a capacidade funcional se estabelece como o conceito de saúde mais adequado para manejar o cuidado à saúde do idoso.

Assumir como objetivo isolado identificar e tratar doenças em idosos significa duas importantes limitações. Em primeiro lugar, é muito comum que as doenças manifestem apresentações atípicas, dificultando o diagnóstico e nos obrigando a procurar manifestações inexistentes ou incomuns em outras faixas etárias - por exemplo, uma infecção urinária, que pode ser manifesta principalmente, às vezes unicamente, por confusão mental. Em segundo lugar, é bastante freqüente nesta população o aparecimento de problemas no formato de síndromes, ou seja, um conjunto de sinais e sintomas comuns a várias doenças, muitas vezes crônicas, o que acaba por fazer com que o único objetivo do geriatra seja controlar suas manifestações, uma vez que, por sua cronicidade, não há cura possível.

Como o principal fator de risco associado aos problemas de saúde do idoso é a própria idade e a multiplicidade de doenças crônicas é uma característica freqüente entre os idosos, a estratégia de cuidados deve ser necessariamente distinta em relação à empregada nas demais faixas etárias. A abordagem tradicional, focada em uma queixa principal, e o hábito médico de reunir todas as queixas e os sinais em um 
único diagnóstico até podem ser adequados ao adulto jovem. Contudo, não se aplicam ao idoso.

A moderna tecnologia geriátrica recomenda que o idoso seja acompanhado com o objetivo central de monitorar seus problemas de saúde, com vistas à estabilização do quadro, buscando-se a manutenção de sua capacidade funcional. Visa-se, deste modo, a criar condições para que o idoso possa usufruir a ampliação de seu tempo de vida com manutenção da qualidade, ao invés da tentativa de cura da doença, pois tal objetivo, pela cronicidade destas morbidades, está fora do horizonte de possibilidades de intervenção médica.

A aplicação do aporte epidemiológico e a ênfase nas ações preventivas fazem com que esta nova abordagem de saúde do idoso favoreça a redução dos custos assistenciais, pois confere prioridade à tecnologia do conhecimento, ao invés da tecnologia das máquinas e imagens. O entendimento dessa lógica, de conferir ênfase na estabilização do quadro das enfermidades do idoso, induz a uma concepção assistencial distinta, com conseqüente reorganização dos serviços de saúde.

A nova realidade demográfica e epidemiológica brasileira aponta para a urgência de mudanças e inovação nos paradigmas de atenção à saúde da população idosa e reclama estruturas criativas e inovadoras, com propostas de ações diferenciadas, de modo que o sistema ganhe efetividade e o idoso possa usufruir integralmente os anos proporcionados pelo avanço da ciência. Já perdemos muito tempo acreditando que ainda somos um país jovem, sem dar o devido crédito às informações demográficas que mostram e projetam o envelhecimento da população. Sabe-se que viver mais é importante na medida em se agregue qualidade aos anos adicionais de vida.

Esta abordagem faz parte de várias linhas de pesquisas e de aplicação empírica nos serviços de saúde da Universidade Aberta da Terceira Idade da Universidade do Estado do Rio de Janeiro (UnATI/UERJ), e está ajustada com o que existe de mais atual na moderna prática gerontológica. Vida plena na maturidade é o mote da celebração dos 15 anos da UnATI/UERJ, que desenvolve esforços para que os novos conceitos se ampliem e se consolidem. 
1 